J. Amer. Soc. Hort. Sci. 116(4):676-679. 1991.

\title{
Role of the Gynoecium in Cytokinin-induced Carnation Petal Senescence
}

\author{
William R. Woodson and Amanda S. Brandt \\ Department of Horticulture, Purdue University, West Lafayette, IN 47907 \\ Additional index words. benzyladenine, Dianthus caryophyllus, ethylene
}

\begin{abstract}
Treatment of cut carnation (Dianthus caryophyllus L. 'White Sim') flowers with the synthetic cytokinin benzyladenine $(\mathrm{BA})$ at concentrations $>1.0 \mu \mathrm{M}$ induced premature petal senescence. Flowers treated with $100 \mu \mathrm{M}$ BA exhibited elevated ethylene production in styles and petals before untreated flowers. The gynoecia of BA-treated flowers accumulated 1-aminocyclopropane-1-carboxyllc acid (ACC) and enlarged before untreated flowers. Removal of the gynoecium (ovary and styles) or styles prevented BA-induced petal senescence and resulted in a substantial delay in petal senescence. In contrast, removal of the gynoecium had no effect on timing of petal senescence in flowers held in water. These results indicate BA stimulates petal senescence by inducing premature ACC accumulation and ethylene production in the gynoecium.
\end{abstract}

The senescence of carnation flowers is associated with a substantial increase in ethylene production (Nichols, 1966, 1968). This increase in ethylene plays an important role in regulating the processes of petal senescence, including changes in gene expression (Borochov and Woodson, 1989; Lawton et al., 1990; Woodson and Lawton, 1988). While the petals account for a large amount of the ethylene produced by carnation flowers, other floral tissues, including the gynoecium, produce a significant amount of ethylene (Nichols, 1977). Indeed, when expressed on a fresh-weight basis, the gynoecium often exhibits rates of ethylene production that exceed those of petals. The finding that the ethylene precursor ACC accumulates in the gynoecium before ACC accumulation or the onset of ethylene production by the petals indicates that tissue may play a role in the regulation of ethylene production and senescence of the flower (Hsieh and Sacalis, 1986; Veen and Kwakkenbos, 1984). Interestingly, extracts from aging carnation gynoecia have been found to induce ethylene production and senescence of isolated carnation petals (Sacalis et al., 1983). In spite of these findings, the role of the gynoecium in the regulation of carnation petal senescence is not clear. Mor et al. (1980) reported that removal of the gynoecium from presenescent carnation flowers did not alter the time of petal senescence, and, furthermore, isolated petals senesced at the same time as those on intact flowers. Petal senescence of carnations is induced prematurely following pollination (Nichols, 1977; Nichols et al., 1983). In this case, a role for the gynoecium in the regulation of petal senescence is clear. Pollinated styles exhibit a large increase in ACC content and ethylene production and transmit senescence-inducing factors, including ACC, to the petals (Nichols et al., 1983; Reid et al., 1984).

The senescence of carnation flowers is often delayed by treatment with cytokinins (Cook et al., 1985; Eisinger, 1977; Mor et al., 1983). A decline in endogenous cytokinins during petal senescence has led to the suggestion that cytokinin naturally plays a role in regulating petal senescence (Mayak and Halevy, 1970; Van Staden et al., 1987). Cytokinins have not been adopted as commercial vase solutions since results are often variable. Close examination of the literature reveals that in some cases

Received for publication 24 Oct. 1990. This research was supported in part by grants from the National Science Foundation (DCB-8911205) and the Fred C. Gloeckner Foundation. Publication no. 12,794 of the Purdue Univ. Agricultural Experiment Station. The cost of publishing this paper was defrayed in part by the payment of page charges. Under postal regulations, this paper therefore must be hereby marked advertisement solely to indicate this fact. cytokinins have been shown to stimulate petal senescence (Eisinger, 1977; Van Staden and Joughin, 1988). We now report results that indicate the gynoecium plays a critical role in determining the response of carnations to exogenously supplied cytokinin.

\section{Materials and Methods}

Plant material. Flowers of 'White Sire' carnation were harvested from greenhouse-grown plants when petals were reflexed $90^{\circ}$ with respect to the plane of the calyx. Growing conditions were as described by Woodson (1987). Flowers were recut to a stem length of $10 \mathrm{~cm}$ and held in either distilled (DI) water or benzyladenine (BA) in the range of 0 to $100 \mu \mathrm{M}$. Solutions were changed daily.

Ethylene production. The production of ethylene by individual flowers was measured by enclosing flowers in 1-liter gastight containers and sampling the head space following a 1-h incubation period. Individual flower parts were placed in $25-\mathrm{ml}$ gas-tight vials and sampled for ethylene after $1 \mathrm{~h}$. Ethylene in gas samples was measured by gas chromatography using a Varian 3300 GC (Varian, Palo Alto, Calif. ) with an alumina column coupled to a flame ionization detector.

ACC analysis. Petal tissue ( $2 \mathrm{~g}$ fresh weight) was homogenized in $10 \mathrm{ml}$ of $80 \%$ ethanol using a Polytron homogenizer. The homogenate was centrifuged at $10,000 \times \mathrm{g}$ for $10 \mathrm{~min}$, the supernatant saved, and the resulting pellet reextracted with $10 \mathrm{ml}$ of $80 \%$ ethanol. Following centrifugation, the supernatants were combined and evaporated to dryness. The resulting residue was resuspended in $2 \mathrm{ml}$ of DI water. ACC was assayed following conversion to ethylene as described by Wang and Woodson (1989).

All treatments were replicated three times and experiments repeated at least three times.

\section{Results}

Preliminary attempts to delay the senescence of carnation flowers with cytokinins were not consistent; therefore, we assessed the effects of various concentrations of BA on the vase life of flowers. Treatment of flowers through the vase solution with $1.0 \mu \mathrm{M}$ BA significantly delayed carnation petal senescence compared with water and all other cytokinin concentrations (Fig. 1). Cytokinin concentrations $>1.0 \mu \mathrm{M}$ resulted in premature petal senescence. Flowers treated with $1.0 \mu \mathrm{M} \mathrm{BA}$ produced less ethylene throughout the experimental period than flowers treated with lower or higher BA concentrations (Fig. 
2). The ethylene climacteric occurred earlier in flowers treated with $>1.0 \mu \mathrm{M}$ BA. These results confirm the variable effect of BA on flower senescence with concentration and are consistent with previous examples of responses of carnations to exogenous application of cytokinins (Eisinger, 1977; Van Staden and Joughin, 1988).

Senescence of carnation petals is associated with growth of the ovary (Nichols, 1976). In preliminary experiments we observed that BA-treated flowers exhibited significant enlargement of the ovaries compared with untreated controls. To quantify this effect, we assessed the influence of BA concentrations on growth of the ovaries. BA concentrations $>1.0 \mu \mathrm{M}$ promoted growth of the ovaries (Fig. 3), as indicated by increased fresh weight.

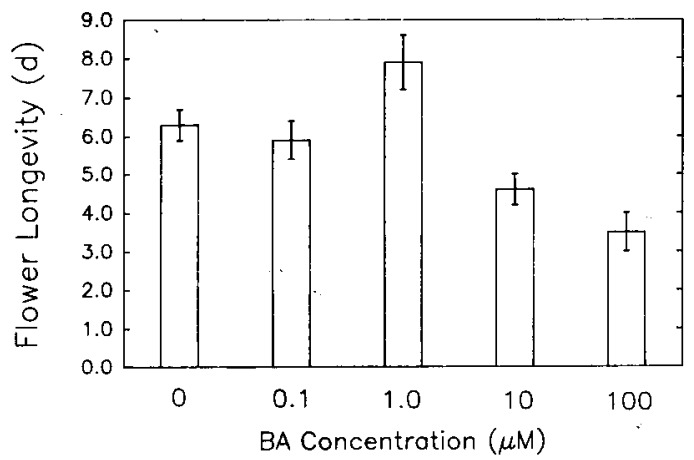

Fig. 1. Influence of BA concentration on flower petal longevity. Flowers were harvested at anthesis and held in BA solutions. Senescence was judged by petal in-rolling and irreversible wilting. Means of three flowers \pm SE.

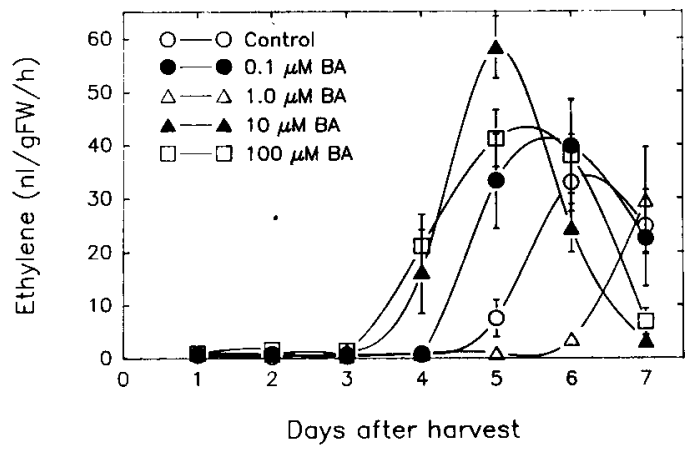

Fig. 2. Influence of BA concentration on ethylene production by carnation flowers. Ethylene production was measured daily following harvest at anthesis. Means of three flowers $\pm S E$.

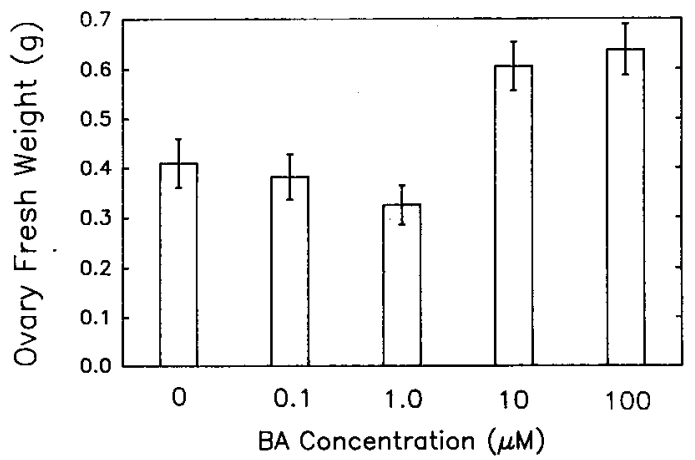

Fig. 3. Influence of BA concentration on growth of ovaries; their fresh weight was measured 7 days after harvest and following treatment with BA. Means of three flowers \pm SE.
In another experiment, we determined the influence of BA on ethylene production and ACC content of petals, styles, and the ovary. Treatment of flowers with $100 \mu \mathrm{M} \mathrm{BA}$ induced an increase in ethylene production by styles and ovaries that preceded the ethylene climacteric in these tissues by 2 to 3 days relative to those held in water (Fig. 4). The BA-induced increase in ethylene production by the gynoecia preceded the increase in petal ethylene by 1 day. Treatment of flowers with $100 \mu \mathrm{M} \mathrm{BA}$ resulted in a substantial increase in ACC in petals, styles, and the ovary that preceded the increase in $\mathrm{ACC}$ in control flowers (Fig. 5). An increase in ACC content of styles was evident following 2 days in BA. Flowers set in water did not accumulate ACC until 5 days after harvest. The concentration of ACC in the ovaries of BA-treated flowers reached levels $>10$ times that of the control flowers. Thus, treatment of flowers with BA results in the accumulation of ACC in the gynoecia before the increase in petal ethylene production and the onset of visible symptoms of senescence.

The growth of the ovary, coupled with the substantial accumulation of ACC and production of ethylene by BA-treated carnation gynoecia, led us to speculate that this tissue may play a role in BA-induced petal senescence. We, therefore, treated flowers with $100 \mu \mathrm{M}$ BA following removal of the styles or entire gynoecium. Removal of the styles or gynoecium from flowers held in water did not significantly alter their ethylene

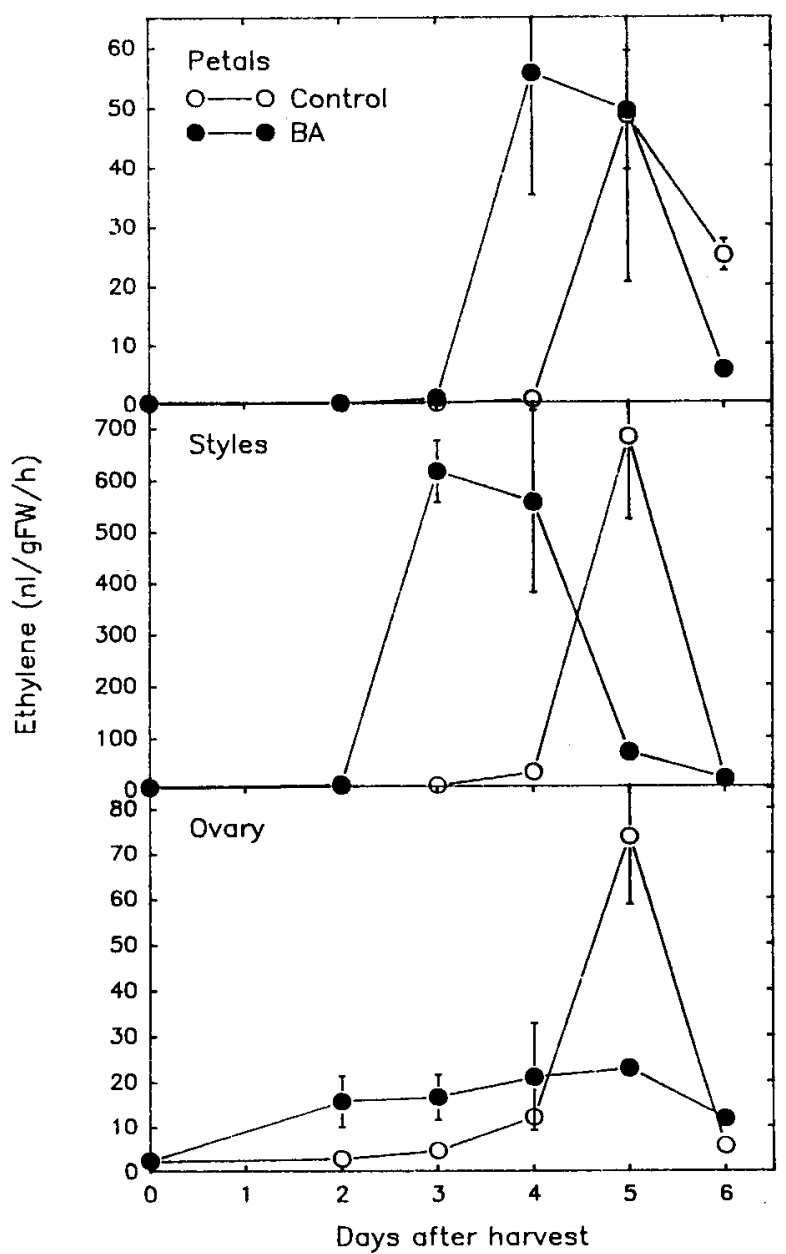

Fig. 4. Influence of BA on ethylene production by petals, styles, and ovaries of carnation flowers. Individual flower parts were removed from intact flowers at various times after harvest and their ethylene production measured. Means of three flowers \pm SE. 


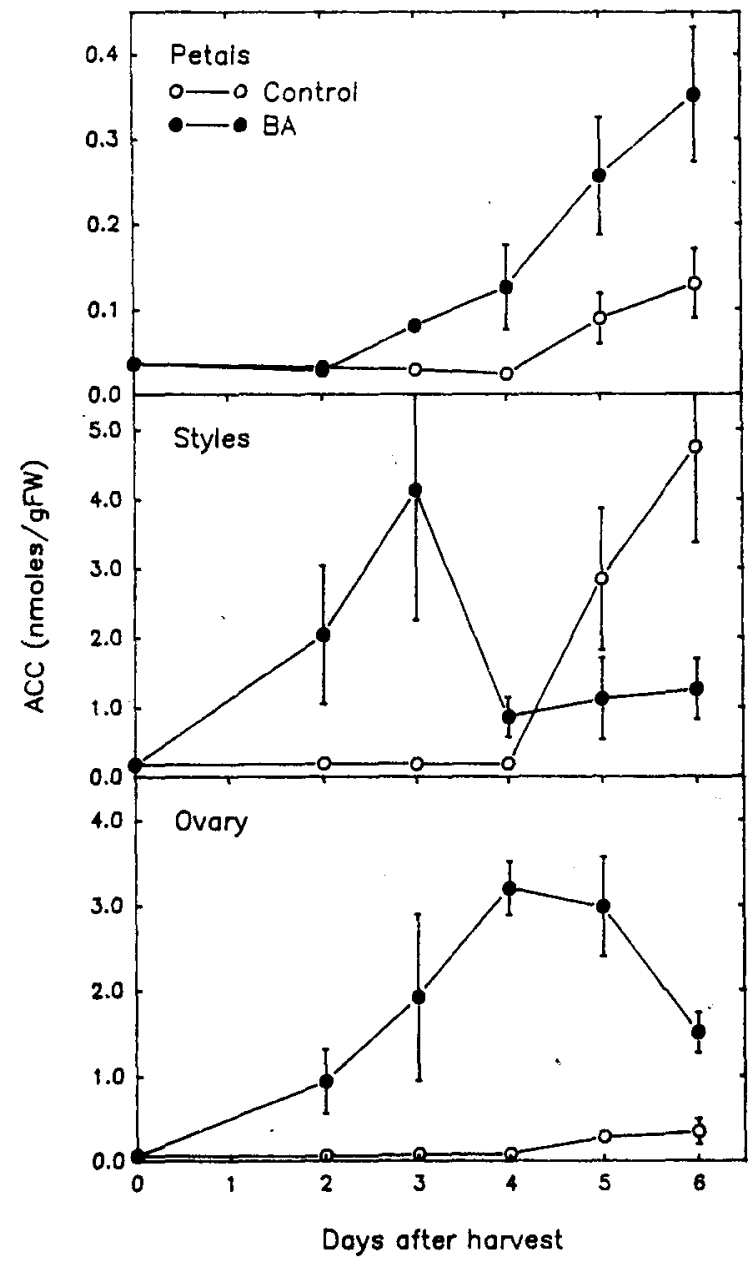

Fig. 5. Influence of BA on ACC content of petals, styles, and ovaries of carnation flowers. Means of three flowers \pm SE.

production or senescence (Fig. 6). These flowers exhibited an increase in ethylene production beginning 5 days after harvest and showed symptoms of senescence at the same time. In contrast, flowers treated with $100 \mu \mathrm{M} \mathrm{BA}$ did not exhibit an ethylene climacteric throughout the experimental period (12 days) when styles or gynoecia were removed, in contrast to intact flowers treated with BA, which increased in ethylene production 2 to 3 days after treatment and exhibited symptoms of senescence associated with this ethylene climacteric.

\section{Discussion}

Senescence of carnation flower petals is often delayed following application of cytokinins (Cook et al., 1985; Eisinger, 1977; Mor et al., 1983). A decline in endogenous levels of cytokinin-like compounds during petal senescence led to the suggestion that these compounds normally function as antisenescence hormones (Mayak and Halevy, 1970; Van Staden et al., 1987). In spite of this function, cytokinins are rarely used commercially to retard senescence due to variable results. The research reported here confirms the variability in cytokinin response and indicates concentrations as low as $10 \mu \mathrm{M}$ supplied through the vase solution actually promote senescence. Our results indicate that cytokinin-induced senescence is modified through an interaction with the gynoecium that leads to ACC accumulation in these tissues and premature ethylene production in both the gynoecium and petals.

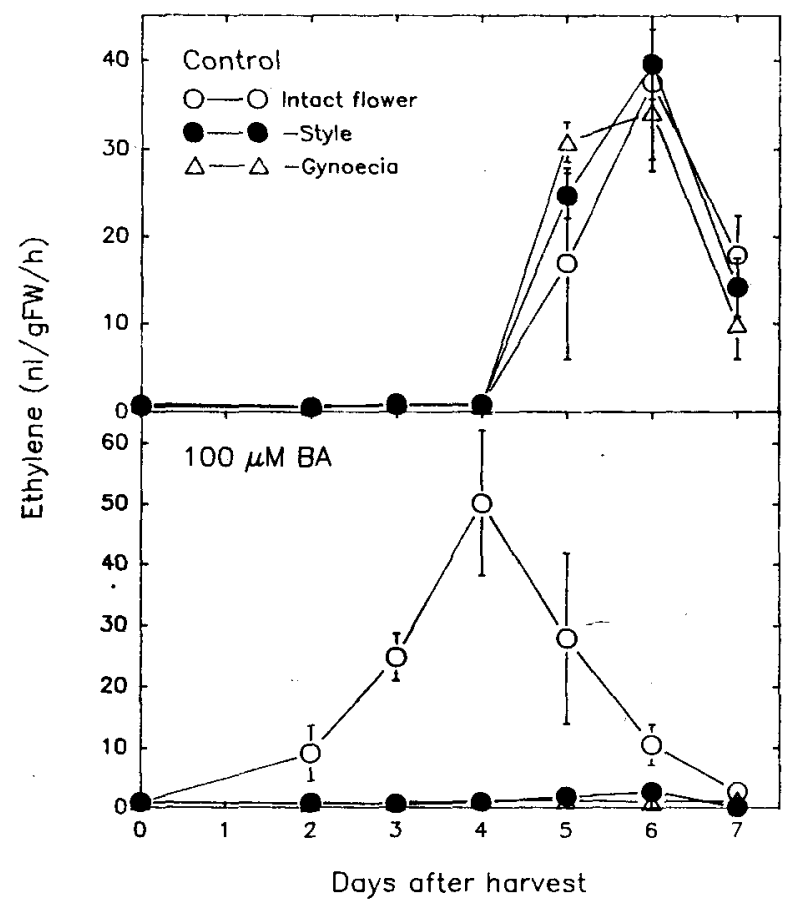

Fig. 6. Effect of style or gynoecium removal on the ethylene production of BA-treated carnation flowers. The style or gynoecium was removed from flowers the day of harvest and flowers were treated with water or $100 \mu \mathrm{M}$ BA. Means of three flowers \pm SE.

Mor et al. (1983) reported that when $100 \mu \mathrm{M}$ BA was applied to excised petals, they were subsequently incapable of converting ACC to ethylene or responding to ethylene by the production of autocatalytic ethylene or senescence. Our results with intact flowers are different, leading to the speculation that other tissues in some way modify the petals' response to applied cytokinins. One possible explanation of our results is that BA-treated flowers have gynoecia with greater sink strength, and thus petal senescence is hastened as a result of nutrient mobilization. This possibility is supported by the observation that ovary growth was promoted by BA treatment. Others have shown that the onset of petal senescence is associated with movement of nutrients from petals to reproductive tissues (Nichols and Ho, 1975). Furthermore, treatments that delay petal senescence often do so at the expense of ovary growth (Mor et al., 1980), indicating a relationship exists between ovary growth and petal senescence. The finding that wilting carnation flowers have the highest cytokinin activity in the gynoecia leads to the speculation that cytokinins may naturally play a role in promoting sink strength in this tissue (Van Staden and Dimalla, 1980). When ovaries were removed from BA-treated flowers, cytokinin application did not promote senescence. While this result supports the hypothesis of increased sink strength, the fact that removal of styles alone prevented BA-induced petal senescence casts doubt on this conclusion, particularly in light of the limited sink strength of this tissue.

While cytokinins have been shown to inhibit ethylene synthesis in isolated petals (Mor et al., 1983), other tissues often respond to cytokinins by an increase in ethylene production (Lau and Yang, 1975; Suttle, 1986). This cytokinin response is often further stimulated by $\mathrm{Ca}^{2+}$ or auxin (Lau and Yang, 1973, 1975). One mechanism by which cytokinins stimulate ethylene production prevents the conjugation of free auxin, thus increasing the auxin pool available for inducing ethylene production (Yip 
and Yang, 1986). Cytokinin-induced ethylene production appears to be mediated through the induction of ACC synthase activity. Sato and Theologis (1989) recently reported that BA induced the accumulation of ACC synthase mRNA in zucchini squash and that this could be further stimulated by auxin. Following application of $100 \mu \mathrm{M} \mathrm{BA}$, intact flowers produced elevated ethylene before untreated controls. This difference appears to be the result of BA-induced accumulation of ACC in reproductive tissue, and particularly styles. Transport of ACC to other tissues, including the petals, or a more direct effect of ethylene production by the pistil could lead to elevation of ethylene production in other flower organs. The fact that removal of styles was sufficient to prevent the BA-induced senescence strongly implicates this tissue in the regulation of this response. Interestingly, Sacalis (1989) recently reported that the induction of carnation petal senescence by auxin treatment could be prevented by removal of the gynoecium. A possible explanation for our results is that, in intact flowers, cytokinins prevent the conjugation of auxin in the gynoecia which, in turn, leads to an increase in ACC synthase activity and an accumulation of ACC; upon transport to the petals, ACC then induced ethylene production and petal senescence. However, the finding of Mor et al. (1983) that isolated petals treated with BA were incapable of producing ACC or converting ACC to ethylene casts doubt on this hypothesis. Therefore, the production of ACC in the gynoecium in and of itself is insufficient to explain our results. Likely, other senescence-inducing factors, in addition to ACC, are produced in the BA-treated gynoecium and mobilized to the petals. Clearly, the interaction of auxin and cytokinins in the regulation of petal senescence warrants further investigation.

\section{Literature Cited}

Borochov, A. and W.R. Woodson. 1989. Physiology and biochemistry of flower petal senescence. Hort. Rev. 11:15-43.

Cook, D., M. Rasche, and W. Eisinger. 1985. Regulation of ethylene biosynthesis and action in cut carnation flower senescence by cytokinins. J. Amer. Soc. Hort. Sci. 110:24-27.

Eisinger, W. 1977. Role of cytokinins in carnation flower senescence. Plant Physiol. 59:707-709.

Hsieh, Y. and J.N. Sacalis. 1986. Levels of ACC in various floral portions during aging of cut carnations. J. Amer. Soc. Hort. Sci. 111:942-944.

Lau, O.L. and S.F. Yang. 1973. Mechanism of a synergistic effect of kinetin on auxin-induced ethylene production. Plant Physiol. 51:10111014.

Lau, O.L. and S.F. Yang. 1975. Interaction of kinetin and calcium in relation to their effect on stimulation of ethylene production. Plant Physiol. 55:738-740.

Lawton, K. A., K.G. Raghothama, P.B. Goldsbrough, and W.R. Woodson. 1990. Regulation of senescence-related gene expression in carnation flower petals by ethylene. Plant Physiol. 93:1370-1375.

Mayak, S. and A.H. Halevy. 1970. Cytokinin activity in rose petals and its relation to senescence. Plant Physiol. 46:497-499.

Mor, Y., M.S. Reid, and A.M. Kofranek. 1980. Role of the ovary in carnation senescence. Scientia Hort. 13:377-383.

Mor, Y., H. Spiegelstein, and A.H. Halevy. 1983. Inhibition of eth- ylene biosynthesis in carnation petals by cytokinin. Plant Physiol. 71:541-546.

Nichols, R. 1966. Ethylene production during senescence of flowers. J. Hort. Sci. 41:279-290.

Nichols, R. 1968. The response of carnations to ethylene. J. Hort. Sci. 43:335-349.

Nichols, R. 1976. Cell enlargement and sugar accumulation in the gynoecium of the glasshouse carnation induced by ethylene. Planta $130: 47-52$

Nichols, R. 1977. Sites of ethylene production in the pollinated and unpollinated senescing carnation inflorescence. Planta 135:155-159.

Nichols, R. and L.C. Ho. 1975. An effect of ethylene on the distribution of ${ }^{14} \mathrm{C}$-sucrose from the petals to other parts in the senescent cut inflorescence of Dianthus caryophyllus. Ann. Bot. 39:433-438.

Nichols, R., G. Bufler, Y. Mor, D.W. Fujino, and M.S. Reid. 1983. Changes in ethylene production and 1-aminocyclopropane-1-carboxylic acid content of pollinated carnation flowers. J. Plant Growth Regulat. 2:1-8.

Reid, M.S., D.W. Fujino, N.E. Hoffman, and C.S. Whitehead. 1984. 1-aminocyclopropane-1-carboxylic acid (ACC)-the transmitted stimulus in pollinated flowers. J. Plant Growth Regulat. 3:189-196.

Sacalis, J.N. 1989. Effect of gynoecium excision on auxin-mediated promotion of petal senescence in cut carnation flowers. J. Plant Physiol. 133:734-737.

Sacalis, J. N., G. Wulster, and H. Janes. 1983. Senescence in isolated carnation petals: Differential response of various petal portions to ACC, and effects of uptake of exudate from excised gynoecia. Z. Pflanzenphysiol. 112:7-14.

Sate, T. and A. Theologis. 1989. Cloning the mRNA encoding ACC synthase, the key enzyme for ethylene biosynthesis in plants. Proc. Natl. Acad. Sci. 86:6621-6625.

Suttle, J.C. 1986. Cytokinin-induced ethylene biosynthesis in nonsenescing cotton leaves. Plant Physiol. 82:930-935.

Van Staden, J. and G.G. Dimalla. 1980. The effect of silver thiosulfate on the physiology of cut carnations. II. Influence on endogenous cytokinins. Z. Pflanzenphysiol. 99:19-26.

Van Staden, J. and J.I. Joughin. 1988. Cytokinins in cut carnation flowers. IV. Effects of benzyladenine on flower longevity and the role of different longevity treatments on its transport following application to the petals. Plant Growth Regulat. 7:117-128.

Van Staden, J., B.C. Featonby-Smith, S. Mayak, H. Spiegelstein, and A.H. Halevy. 1987. Cytokinins in cut carnation flowers. II. Relationship between endogenous ethylene and cytokinin levels in the petals. Plant Growth Regulat. 5:75-86.

Veen, J. and A.A.M. Kwakkenbos. 1984. Role of ethylene in distribution of assimilates in cut carnations. J. Plant Physiol. 115:389396.

Wang, H. and W.R. Woodson. 1989. Reversible inhibition of ethylene action and interruption of petal senescence in carnation flowers by norbornadiene. Plant Physiol. 89:434-438.

Woodson, W.R. 1987. Changes in mRNA and protein populations during the senescence of carnation petals. Physiol. Plantarum 71:495502 .

Woodson, W.R. and K.A. Lawton. 1988. Ethylene-induced gene expression in carnation petals. Relationship to autocatalytic ethylene production and senescence. Plant Physiol. 87:498-503.

Yip, W. and S.F. Yang. 1986. Effect of thidiazuron, a cytokinin-active urea derivative, in cytokinin-dependent ethylene production systems. Plant Physiol. 80:515-519. 